\title{
Nitric Oxide is an Upstream Signal Involved in the Multisignalling Network during the Russian Wheat Aphid Resistance Response and its Application Enhances Resistance
}

\author{
M.J. MOLOI*, A.J. VAN DER WESTHUIZEN and A. JANKIELSOHN \\ University of the Free State, Bloemfontein, Free State, South Africa \\ (Received 5 August 2013; Accepted 28 March 2014; \\ Communicated by A. Goyal)
}

\begin{abstract}
The Russian wheat aphid (RWA) is serious pest of wheat in South Africa since its discovery in 1978. Nitric oxide (NO) plays an essential role in the RWA resistance response of wheat. This study was conducted to establish whether NO acts upstream or downstream of salicylic acid (SA) during the RWA defence response and also to investigate the effect of NO application on RWA control. In addition, the involvement of peroxynitrite in the RWA resistance response of wheat was studied. Resistant and/or susceptible plants grown under controlled conditions $\left(25 \pm 2^{\circ} \mathrm{C}\right)$ were used. Using a NO donor, sodium nitroprusside (SNP), and a NO production inhibitor, sodium tungstate (NaWO4), it was proved that $\mathrm{NO}$ acts upstream of SA during the RWA resistance response of wheat. Furthermore, a significant decrease in RWA intrinsic increase rate ( $\mathrm{rm}$ ) and disease symptom development after SNP application emphasized the role of NO in the RWA resistance responses. High levels of peroxynitrite (by-product of NO) content in the RWA infested resistant plants and inhibition of secondary defence enzymes $(\beta-1,3$-glucanase and peroxidase) after urate (inhibitor of peroxynitrite production) application proposed the involvement of this molecule in the signalling events of the RWA resistance.
\end{abstract}

Keywords: nitric oxide, peroxynitrite, resistance, Russian wheat aphid, salicylic acid

\section{Introduction}

The Russian wheat aphid (Diuraphis noxia, RWA) has been an important pest of wheat since 1978 when it was first reported in South Africa (Walters et al. 1980). Aphids can have a dramatic negative impact on their host plant, partly due to their capacity for extremely rapid population growth (Goggin 2007). The RWA feeding symptoms on susceptible wheat include white, yellow, purple to reddish-purple longitudinal chlorotic streaks and severe rolling on the leaves, which result in lower grain yield/poor quality and even death in the case of extreme infestation (Walters et al. 1980).

\footnotetext{
*Corresponding author; E-mail: 1996688105@ufs4life.ac.za
} 
Extensive research on the RWA resistance responses of wheat has been conducted in our lab. One of the events during the RWA resistance response is the extra production of nitric oxide (NO) to high levels. Nitric oxide plays an essential role in the early signalling events leading to induction of the secondary defence responses of RWA resistance such as the increased intercellular $\beta$-1,3-glucanase and peroxidase activities (Moloi and van der Westhuizen 2014), which are usually used as biochemical markers of systemic acquired resistance (SAR) in plants (Fritig et al. 1998). It was previously discovered that nitrate reductase (NR) is a key enzyme responsible for NO production during the RWA resistance responses. This finding was confirmed with NR inhibition studies, which showed that NR inhibition consequently leads to a significant reduction in NO production (Moloi and van der Westhuizen 2014). Preliminary studies using nitric oxide synthase (NOS) inhibitor further substantiated that NR is the main source of NO production during RWA resistance response (unpublished data).

Salicylic acid (SA) is required for the establishment of SAR (Hayat et al. 2010). A cooperative action between NO and SA has been suggested (Klessig et al. 2000). Although contradictory, some studies suggest NO to act upstream SA during resistance (Song and Goodman 2001) and others suggest the opposite (Zottini et al. 2007; Gaupels et al. 2008). Involvement of SA in the RWA resistance response network has been established. A time-dependant study showed that the RWA infested resistant plants produce higher SA levels than susceptible plants. This selective induction was only observed from 48 hours post infestation (h.p.i) and coincided with high peroxidase activity (Mohase and van der Westhuizen 2002).

In addition, Moloi and van der Westhuizen (2006) indicated that the reactive oxygen species (ROS) and ROS generating enzymes are involved in the early events of the RWA resistance response. The ROS and NO may rapidly react in the absence of enzyme catalysis to form a powerful oxidizing agent, peroxynitrite (Blough and Zafiriou 1985; Saito et al. 2006).

On the basis of the above described work, this study was conducted to explore whether NO acts upstream or downstream of SA and also to investigate involvement of peroxynitrite during the RWA resistance response. Since previous studies clarified the importance of NO in the RWA resistance, the effect of sodium nitroprusside (SNP, a NO donor) application was investigated as a possible tool for RWA control. Parameters used in this case were the intrinsic increase rate $\left(r_{m}\right)$ of RWA populations and the RWA feeding symptom development on the leaves.

\section{Materials and Methods}

\section{Plant material}

Resistant wheat (Triticum aestivum L.) (cv. Tugela DN), containing the Dn1 (PI 137739) resistance gene (Du Toit 1989) and/or near-isogenic susceptible wheat (cv. Tugela) were grown under greenhouse conditions $\left(25 \pm 2^{\circ} \mathrm{C}\right)$. 


\section{The RWA stock colonies}

The RWA, Diuraphis noxia (Kurdjumov), biotype RWASA1 stock colonies were maintained at the Small Grain Institute of the Agricultural research council (ARC-SGI). These aphids were screened to confirm biotype status and were maintained in gauze cages (gauze73 size: 315 micron) on different wheat cultivars, under greenhouse conditions $\left(25 \pm 2^{\circ} \mathrm{C}\right)$.

\section{Infestation procedure for peroxynitrite and SA content}

Plants (approximately 20) were infested at the early three-leaf stage by scattering approximately 20 aphids per plant. Leaves were harvested after either time periods $(0,3,6,9,12$, $24,48 \mathrm{~h}$ ), frozen in liquid nitrogen and stored at $-20^{\circ} \mathrm{C}$ until used. Only $0.5 \mathrm{~g}$ of frozen leaf tissue was used for peroxynitrite and SA extraction.

\section{Sodium nitroprusside (SNP), sodium tungstate and urate application}

To investigate the relationship between SA and NO, uninfested resistant plants were supplied with Hoagland solution (Hoagland and Arnon 1950) containing 0.15 mM SNP for the duration of the experiment $(48 \mathrm{~h})$ through the roots. If applied to the biological systems, NO donors produce NO and are able to either mimic an endogenous NO-related response or substitute for an endogenous NO deficiency (Floryszak-Wieczorek et al. 2006). Leaves were then harvested for the determination of SA content. Vermiculite was used as a supporting material and this applies to all treatments. The control plants were supplied with Hoagland solution without SNP. The uninfested resistant plants were used here because of their low NO and SA levels as previously discovered (Mohase and van der Westhuizen 2002; Moloi and van der Westhuizen 2014). Therefore, this approach would make it possible to investigate the effect of increased endogenous NO on SA production.

Based on the discovery that NO production mainly depends on the activity of NR, infested resistant plants (which were found to have elevated NR activity and NO production; Moloi and van der Westhuizen 2014) were supplied (through the roots) with a Hoagland solution containing $4.1 \mathrm{mM}$ sodium tungstate $\left(\mathrm{Na}_{2} \mathrm{WO}_{4}\right.$, NR inhibitor) 2 hours prior infestation and was continued for the duration of the experiment $(48 \mathrm{~h})$. The control plants were not treated with tungstate in order to investigate the effect of NO inhibition on SA production. Leaves were then harvested for SA content determination.

Other sets of plants (susceptible and resistant) were supplied with Hoagland solution that was supplemented with different SNP concentrations $(0.1,0.15 \mathrm{mM}$ and $0.5 \mathrm{mM})$ through the roots ( 1 hour prior to RWA infestation). These were used for the RWA intrinsic increase rate $\left(r_{m}\right)$ and disease symptom analysis. Control plants were supplied with Hoagland solution only. In the case where SNP was applied as a seed dressing, seeds were soaked in SNP solutions of different concentrations $(0.1,0.15$ and $0.5 \mathrm{mM})$ for 1 hour before planting. Control seeds were soaked only in distilled water for 1 hour before planting.

The RWA infested resistant plants were treated with $1 \mathrm{mM}$ urate (peroxynitrite inhibitor) in Hoagland solution through the roots ( 2 hours before RWA infestation). Leaves 
were harvested for peroxynitrite content (12 h.p.i), peroxidase and $\beta$-1,3-glucanase (48 h.p.i) activities assays.

\section{Intrinsic increase rate and symptom development}

First instar aphids were obtained from reproducing adult aphids and transferred to separate wheat plants until they reached adult reproductive stage. Plants were then infested at the early three leaf stage with two reproductive adult aphids per plant. Age-specific survival $\left(l_{x}\right)$ of nymphs and adults and age-specific fecundity $\left(\mathrm{m}_{\mathrm{x}}\right)$ were recorded at 24-hour intervals for a period of 72 hours. Intrinsic rate of increase $\left(\mathrm{r}_{\mathrm{m}}\right)$ was determined using the formula:

$$
r_{m}=\operatorname{Ln}\left(R_{o}\right) / T \text { where } R_{0}=\Sigma 1_{x} m_{x} \text { and } T=1_{x} m_{x} x
$$

(x: age at beginning of interval; $1_{\mathrm{x}}$ : age specific survivorship; $\mathrm{m}_{\mathrm{x}}$ : expected daughters; $\mathrm{l}_{\mathrm{x}} \mathrm{m}_{\mathrm{x}}$ : reproductive expectation; $\mathrm{T}$ : mean generation time; $\mathrm{R}_{\mathrm{o}}$ : net reproductive rate) (Birch 1948). Each treatment consisted of six replications.

Symptom development on the leaves was recorded 7 and 14 days after RWA infestation according to a scoring system adopted by Tolmay (1995), whereby plants with a score of $1 \geq 3.5$ represented highly resistant plants (no leaf rolling), $3.6 \geq 6.5$ represented medium resistant plants (chlorosis, but no leaf rolling), and $6.6 \geq 10$ represented susceptible plants (rolled leaves and severe chlorosis). Each treatment consisted of 4 replications.

\section{Extract preparation}

The extract for the peroxynitrite assay was prepared according to the method described by Datta and Sharma (1999) with no modifications.

\section{Collection of intercellular washing fluids (IWF)}

Procedure described by Moloi and van der Westhuizen (2006) was used.

Salicylic acid (SA) content

Total SA (free and conjugated forms) extraction and assay was following a method described by Mohase and van der Westhuizen (2002).

\section{Peroxynitrite $\left(\mathrm{ONOO}^{-}\right)$content}

Peroxynitrite content was measured spectrophotometrically according to Yamasaki and Sakihama (2000). Forty $\mu \mathrm{L}$ plant extract was used.

Intercellular peroxidase activity (EC 1.11.1.7)

A method of Zieslin and Ben-Zaken (1991) was used.

Intercellular $\beta$-1,3-glucanase activity (EC 3.2.1.39)

Original method of Fink et al. (1988) was used according to modifications described by Moloi and van der Westhuizen (2014). 


\section{Protein concentration}

The protein content of the enzyme extracts was determined according to Bradford (1976) using bovine $\gamma$-globulin as standard.

\section{Statistical analysis}

The data were analysed using Sigma Plot version 9.0 of SYSTAT software followed by the $t$-test statements. At least three replications were used.

\section{Results}

Exogenous application of NO donor (SNP) on the uninfested resistant plants led to increased production of SA (44\%) compared to the control plants (Fig. 1a). Inhibition of NR activity with $\mathrm{Na}_{2} \mathrm{WO}_{4}(\mathrm{NR}$ inhibitor) resulted in a significant reduction $(53 \%, P=0.0230)$ in total SA content. However, SA content was still high in the infested resistant than uninfested resistant plants (Fig. 1b).

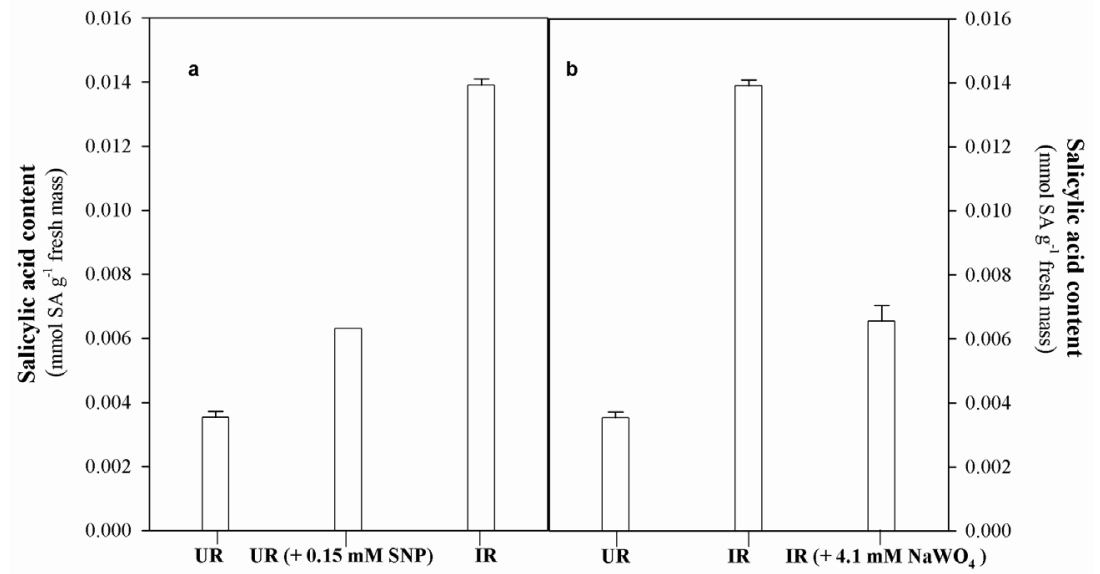

Figure 1. Effect of SNP (a) and $\mathrm{Na}_{2} \mathrm{WO}_{4}$ (b) application on the total SA content of uninfested resistant and RWA infested resistant wheat cultivar. Values are means $\pm \mathrm{SD}(n=3)$.

UR: uninfested resistant; IR: infested resistant

The infested susceptible control plants (i.e. with no SNP application) had significantly higher RWA $\mathrm{r}_{\mathrm{m}}(P=0.036)$ than the infested resistant controls (Fig. 2a, b). Application of different SNP concentrations through the roots had no significant effect on the $r_{m}$ of both susceptible and resistant plants (Fig. 2b). In addition, no correlation between SNP and $\mathrm{r}_{\mathrm{m}}$ was observed $(r=-0.15)$.

In contrast, pre-treatment of seeds with SNP (as a seed dressing) before planting had a substantial impact on $\mathrm{r}_{\mathrm{m}}$ of susceptible plants. The 0.15 and $0.5 \mathrm{mM} \mathrm{SNP}$ application had significant effects in reducing the RWA $r_{\mathrm{m}}$ by $35 \%(P=0.023)$ and $21 \%(P=0.015)$, re- 
spectively. Correlation between the RWA $\mathrm{r}_{\mathrm{m}}$ and treatment of susceptible plants with different SNP concentrations was -0.6. Contrary to root applications, the RWA population was decreased by $20 \%$ and $25 \%$ when 0.15 and $0.5 \mathrm{mM}$ SNP was applied as a seed dressing on resistant plants (Fig. 2a).

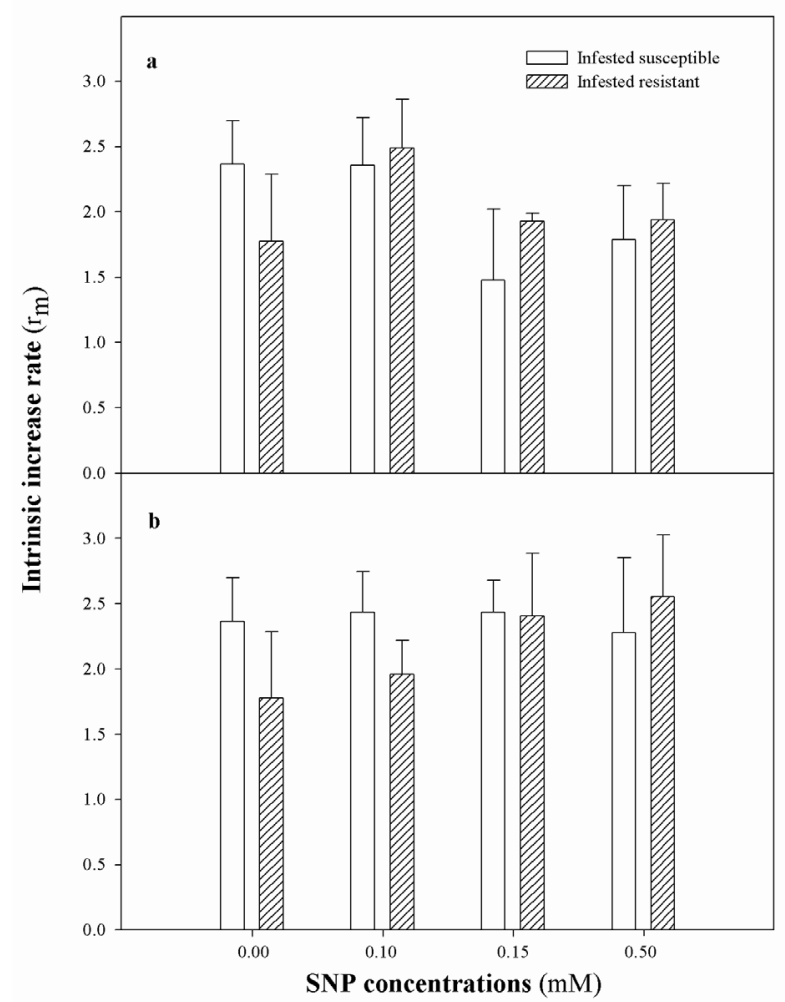

Figure 2. The RWA $\mathrm{r}_{\mathrm{m}}$ (72 h.p.i) of susceptible and resistant wheat cultivars treated with various concentrations of SNP (seed dressing) (a) or root application (b). Values are means $\pm \operatorname{SD}(n=6)$

Susceptible control plants had more severe RWA infestation symptoms than the resistant control plants $168(P=0.015)$ and $336(P=0.0098)$ h.p.i. Application of different concentrations of SNP (root application) had a notable impact on the resistance response of susceptible plants. Significant reduction in the RWA infestation symptoms was observed in the susceptible plants (168 h.p.i) after SNP application. These plants were transiently transformed from being susceptible (S, 7.7), to being medium resistant (MR, 4.7 and 5.4) by $0.15 \mathrm{mM}$ and $0.5 \mathrm{mM}$ SNP application. In addition, correlation between treatment and symptom development on susceptible plants was observed $(r=-0.63)$. No significant changes were brought by SNP treatments in the infested resistant plants (Fig. 3a). 


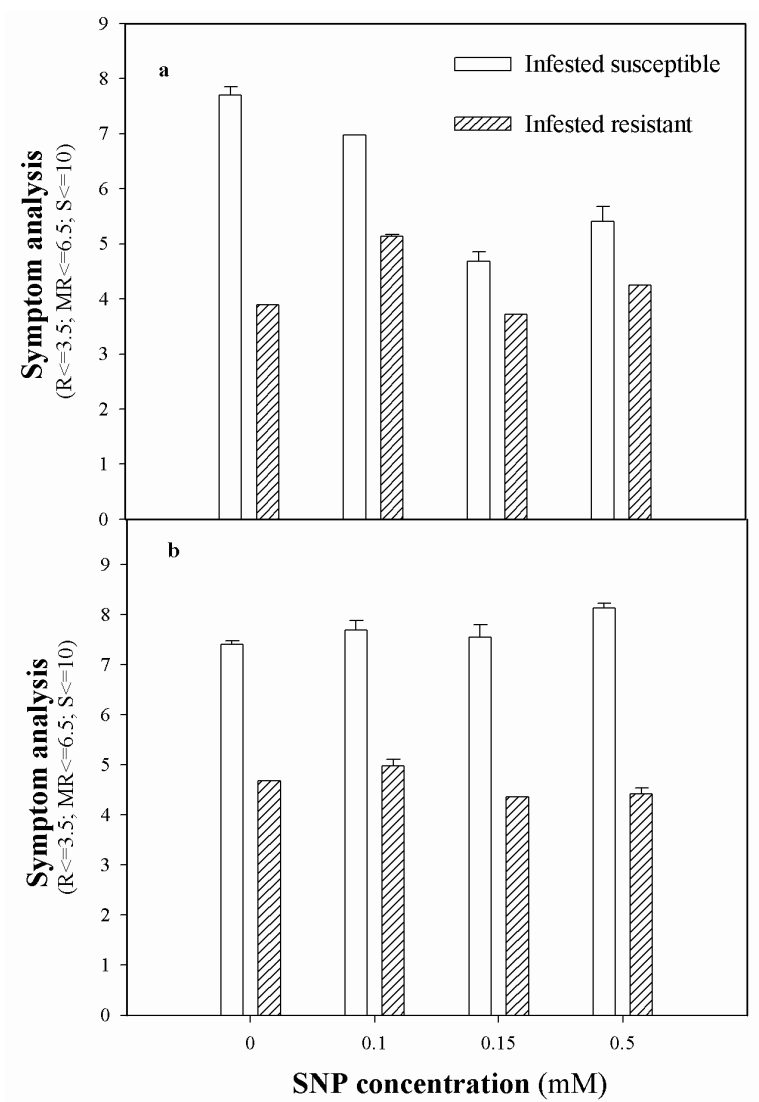

Figure 3. Effect SNP (root application) on symptom/disease development of RWA infested resistant (Tugela DN) and susceptible (Tugela) wheat cultivars 168 (a) and 336 (b) h.p.i. Values are means \pm SD $(n=4)$. S: susceptible, MR: medium resistant, R: highly resistant

Later-on (336 h.p.i), the infested susceptible plants developed more disease symptoms than earlier-on, irrespective of SNP treatments (Fig. 3b).

Selective induction of peroxynitrite to higher levels in the resistant plants was observed. A peak increase representing $45 \%$ was reached 12 hours post infestation (h.p.i) and subsequently dropped. The RWA infested susceptible and control plants had no significant induction (Fig. 4).

Significant reduction in peroxynitrite content ( $47 \%$ decrease) was obtained after urate (selective inhibitor of peroxynitrite production) application on RWA infested resistant plants 12 h.p.i (Fig. 5a). Consequently, urate application further led to substantial inhibition of $\beta$-1,3-glucanase $(51 \%, P=0.0012$, Fig. 5 b) and peroxidase $(53 \%, P=0.0004$, Fig. $5 c)$ activities. 


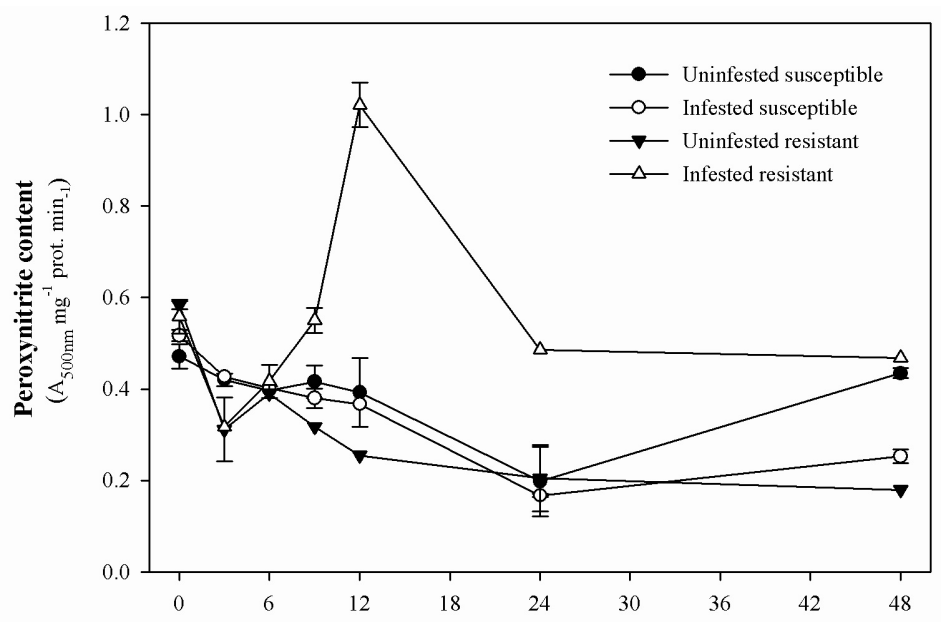

Figure 4. Effect of RWA infestation on the peroxynitrite content of resistant and susceptible wheat cultivars. Values are means $\pm \mathrm{SD}(n=3)$

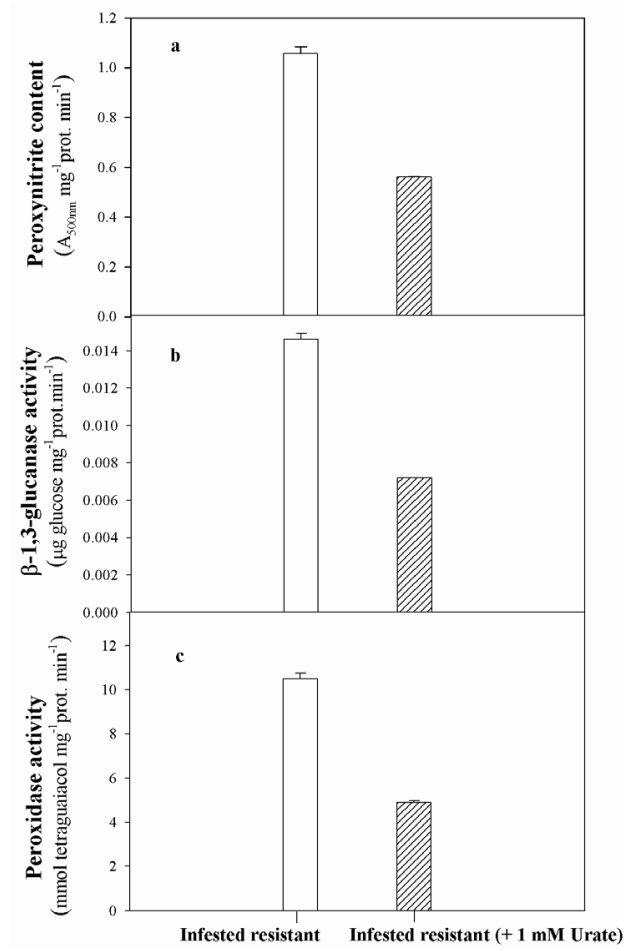

Figure 5. Effect of urate on peroxynitrite content (12 h.p.i; a), intercellular $\beta$-1,3-glucanase (48 h.p.i; b) and peroxidase (48 h.p.i; c) activities of a RWA infested resistant wheat cultivar. Values are means $\pm \operatorname{SD}(n=3)$ 


\section{Discussion}

It was found in previous studies that SA and NO levels increased during the RWA resistance responses. It was also revealed that SA and NO play an important signalling role during the RWA resistance response (Mohase and van der Westhuizen 2002; Moloi and van der Westhuizen 2014). Although these studies are informative, the relationship between the two molecules was not investigated. The current work will provide clarity on this matter. The NO donors are known to mimic an endogenous NO-related response or substitute for an endogenous NO deficiency if applied on biological systems (FloryszakWieczorek et al. 2006). A significant increase in SA content of uninfested resistant plants (which were previously found to have very low NO level; Moloi and van der Westhuizen 2014) following SNP application (Fig. 1a), is an indication that NO acts upstream of SA. Strong evidence that NO production depends on the activity of NR during the RWA resistance response of wheat was previously provided (Moloi and van der Westhuizen 2014). Therefore, substantial decrease in SA production after NR inhibition (Fig. 1b) further confirms that SA acts downstream of NO during RWA resistance. In support, Song and Goodman (2001) revealed that in tobacco, NO-mediated disease resistance requires the action of SA and that NO functions upstream of SA in the SAR signalling pathway. Likewise, Durner et al. (1998) found that administration of NO donors increased total SA levels in susceptible tobacco infected with tobacco mosaic virus. The synergistic effect of SA and NO in decreasing the deleterious effects of biotic and abiotic stress is also suggested (Klessig et al. 2000; Simaei et al. 2011).

The damage resulting from aphid infestation is partly due to their capacity for extremely rapid population growth on their host plant (Goggin 2007). Since the role of NO in the RWA resistance has already been established (Moloi and van der Westhuizen 2014), it would be interesting to know whether exogenous application of NO (SNP) could have any effect on the RWA $\mathrm{r}_{\mathrm{m}}$. This parameter has often been used as an index for herbivore performance (Calvitti and Remotti 1998; Buitenhuis et al. 2004). In addition, alternative host suitability can be quantified using growth rate parameters, such as the $r_{m}$ (Pucherelli et al. 2011). For instance, Jyoti and Michaud (2005) compared the performance of two RWA biotypes (RWA1 and RWA2) on three wheat cultivars using $\mathrm{r}_{\mathrm{m}}$. They noted that $R W A 1$ performed better on the susceptible Trego than on either of the two resistant cultivars, Stanton and Halt, whereas RWA2 performed well on all three cultivars and formed larger colonies. Furthermore, Michaud et al. (2006) also found a reduced performance of $R W A 1$ on resistant cultivars with reproductive rate reduced on resistant cultivars by an average of 32 and $41 \%$. Essentially, Hossein (2010) found significant differences in $r_{m}$ values of RWA on 5 varieties of wheat and concluded that varieties with the highest $r_{m}$ value were susceptible and those with the lowest $r_{m}$ values were considered to be resistant. Higher RWA $r_{m}$ in the susceptible than resistant plants (Fig. 2a, b) further substantiates the role of NO in the signalling events of the RWA resistance responses, because NO production was found to be generally lower in the infested susceptible than resistant plants (Moloi and van der Westhuizen 2014). A significant reduction in the RWA $\mathrm{r}_{\mathrm{m}}$ after SNP application as a seed dressing (Fig. 2a) as opposed to root application proves that the 
method of $\mathrm{NO}$ application is critical in inducing the defence responses of plants. The level of $\mathrm{NO}$ production also plays a vital role in resistance because only the plants with 0.15 and $0.5 \mathrm{mM}$ SNP application had significant reduction in RWA population growth (Fig. 2a). Studies indicate that too high NO donor concentrations can have inhibitory effects. The commonly applied donor concentrations range from 10-500 $\mu \mathrm{M}$ (Modolo et al. 2002; Floryszak-Wieczorek et al. 2006). A negative correlation (-0.6) further substantiates the role of $\mathrm{NO}$ level in the resistance responses. To add on, our preliminary studies showed that a number of RWAs that settled/that were attracted on the plants were significantly reduced by SNP treatment (unpublished data). As a result, this could be a contributing factor to low RWA $r_{m}$.

Nitric oxide application could also enhance resistance by reducing the development of RWA feeding symptoms, which include chlorosis and leaf rolling, on the leaves of susceptible plants (Fig. 3a). A relatively strong correlation of SNP and disease symptoms indicates that NO plays a positive role in resistance. However, it seems that NO application through the roots could only confer a short-term resistance to these plants because its effect diminished later-on (336 h.p.i) (Fig. 3b). These results confirm that application of NO can mimic endogenously produced NO (Floryszak-Wieczorek et al. 2006), further leading to reduction of the RWA $r_{m}$ and RWA feeding symptom development. This, moreover, supports the role of $\mathrm{NO}$ in the RWA resistance response of wheat.

During the defence responses, $\mathrm{NO}$ may very rapidly react with $\mathrm{O}_{2}^{-}$, provided there is sufficient NO to form peroxynitrite in the absence of enzymatic catalysis (Tuteja et al. 2004; Saito et al. 2006). An increase in peroxynitrite formation (9 h.p.i) in the resistant, with a transient peak induction (12 h.p.i; Fig. 4) could therefore be a consequence of high NO production and sufficient ROS production. The suggestion is supported by our previous work, which showed that at this period the SOD activity (responsible for conversion of $\mathrm{O}_{2}^{-}$to $\mathrm{H}_{2} \mathrm{O}_{2}$ ) was already low with high NADPH oxidase activity (responsible for $\mathrm{O}_{2}{ }^{-}$ production) (Moloi and van der Westhuizen 2006; 2008; 2014). Higher induction of peroxynitrite in the infested resistant than susceptible plants strongly suggests involvement of this molecule in the RWA resistance response. Peroxynitrite formation could play an important protective role against oxidative stress by preventing the formation of hydroxyl radical, one of the most deleterious ROS (Wink et al. 1995). In order to further investigate the involvement of peroxynitrite in RWA resistance, plants were treated with urate (a selective inhibitor of peroxynitrite formation) (Alamilo and García-Olmendo 2001). Reduction of peroxynitrite production (Fig. 5a) and consequently inhibition of activities of the secondary defence related enzymes, intercellular $\beta$-1,3-glucanase (Fig. 5b) and peroxidase (Fig. 5c), further substantiate the importance of this molecule in RWA resistance. Reports indicate that peroxynitrite production is involved in the secondary defence responses through induction of PR-1, peroxidase and PAL accumulation in Arabidopsis thaliana infected with a bacterial pathogen Pseudomonas syringae (Durner and Klessig 1999). Activities of these enzymes were not inhibited by urate addition in vitro (not shown), indicating that the observed reduction was not a consequence of direct urate effect. 
From these studies, it can be concluded that peroxynitrite could be involved in the RWA resistance responses as one of the signal molecules in addition to $\mathrm{NO}, \mathrm{H}_{2} \mathrm{O}_{2}$ and $\mathrm{SA}$ (Mohase and van der Westhuizen 2002; Moloi and van der Westhuizen 2006, 2014). During the RWA resistance response of wheat, NO acts upstream of SA. The significant effect of NO application on reduction of RWA population growth and eventually the feeding symptoms further confirm the importance of NO in the RWA resistance.

\section{Acknowledgements}

This work was financially supported by the National Research Foundation (NRF)Thuthuka Researchers in Training (RiT) programme and the University of the Free State (UFS), Bloemfontein, South Africa.

\section{References}

Alamilo, J.M., García-Olmendo, F. 2001. Effects of urate, a natural inhibitor of peroxynitrite-mediated toxicity, in the response of Arabidopsis thaliana to the bacterial pathogen Pseudomonas syringae. Plant Journal 25:529-540.

Birch, L.C. 1948. The intrinsic rate of natural increase of an insect population. J. of Animal Ecology 17:15-26.

Blough, N.V., Zafiriou, D.C. 1985. Reaction of superoxide with nitric oxide to form peroxynitrite in alkaline solution. Inorganic Chem. 24:3504-3505.

Bradford, M.M. 1976. A rapid and sensitive method for the quantitation of microgram quantities of protein utilizing the principle of protein-dye binding. Analytical Biochem. 72:248-254.

Buitenhuis, R., Brodeur, J., Vet, L., Brodeur, J. 2004. Preference and performance of hyperparasitoid Syrphophagus aphidivorus (Hymenoptera: Encyrtidae): Fitness consequences of selecting hosts in live aphids or aphid mummies. Ecological Entomol. 29:648-656.

Calvitti, M., Remotti, P.C. 1998. Host preference and performance of Bemisia argentifolii (Homoptera: Aleyrodidae) on weeds in central Italy. Environmental Entomol. 27:1350-1356.

Datta, R., Sharma, R. 1999. Temporal and spatial regulation of nitrate reductase and nitrite reductase in greening maize leaves. Plant Sci. 144:77-83.

Du Toit, F. 1989. Inheritance of resistance in two Triticum aestivum lines to Russian wheat aphid (Homoptera: Aphididae). J. of Economic Entomol. 82:1251-1253.

Durner, J., Klessig, D.F. 1999. Nitric oxide as a signal in plants. Current Opinion in Plant Biol. 2:369-374.

Durner, J., Wendehnne, D., Klessig, D.F. 1998. Defence gene induction in tobacco by nitric oxide, cyclic GMP, and cyclic ADP-ribose. Proc. Natl Acad. of Sci. USA 95:10328-10333.

Fink, W., Liefland, M., Medgen, K. 1988. Chitinases and $\beta$-1,3-glucanases in the apoplastic compartment of oat leaves (Avena sativa L.). Plant Physiol. 88:270-275.

Floryszak-Wieczorek, J., Milczarek, G., Arasimowicz, M., Ciszewski, A. 2006. Do nitric oxide donors mimic endogenous NO-related response in plants? Planta 224:1363-1372.

Fritig, B., Heitz, T., Legrand, M. 1998. Antimicrobial proteins in induced plant defence. Current Opinion in Immunology 10:16-22.

Gaupels F., Furch, A.C.U., Will, T., Mur, L.A.J., Kogel, K-H., van Bel, A.J.E. 2008. Nitric oxide generation in Vicia fab a phloem cells reveals them to be sensitive detectors as well as possible systemic transducers of stress signals. New Phytolol. 178:634-646.

Goggin, F.L. 2007. Plant-aphid interactions: Molecular and ecological perspectives. Current Opinion in Plant Biol. 10:399-408.

Hayat, Q., Hayat, S., Irfan, M., Ahmad, A. 2010. Effect of exogenous salicylic acid under changing environment: A review. Environmental and Exp. Bot. 68:14-25.

Hoagland, D.R., Arnon, D.I. 1950. The water-culture method for growing plants without soil. California Agriculture Experimental Station Circular 347:1-32. 
Hossein, K.M. 2010. Field assessment of antibiosis resistance of different wheat cultivars to the Russian wheat aphid, Diuraphis noxia (Mordvilko) (Homoptera: Aphididae) at stem elongation growth stage. Munins Entomology and Zoology 5:1060-1065.

Jyoti, J.L., Michaud, J.P. 2005. Comparative biology of a novel strain of Russian wheat aphid (Homoptera: Aphididae) on three wheat varieties. J. of Economic Entomol. 98:1032-1039.

Klessig, D.F., Durner, J., Noad, R., Navarre, D.A., Wendehenne, D., Kumar, D., Zhou, J.M., Shah, J., Zhang, S., Kachroo, P., Trifa, Y., Pontier, D., Lam, E., Silva, H. 2000. Nitric oxide and salicylic acid signalling in plant defense. Proc. Natl Acad. of Sci. USA 97: 8849-8855.

Michaud, J.P., Jyoti, J.L., Qureshi, J.A. 2006. Positive correlation of fitness with group size in two biotypes of Russian what aphid (Homoptera: Aphididae). J. of Economic Entomol. 99:1214-1224.

Modolo, L.V., Cunha, F.Q., Braga, M.R., Salgado, I. 2002. Nitric oxide synthase-mediated phytoalexin accumulation in soybean cotyledons in response to the Diaporthe phaseolorum f. sp. meridionalis elicitor. Plant Physiol. 130:1288-1297.

Mohase, L., van der Westhuzen, A.J. 2002. Salicylic acid is involved in resistance responses in the Russian wheat aphid-wheat interaction. J. of Plant Physiol. 159:585-590.

Moloi, M.J., van der Westhuizen, A.J. 2006. The reactive oxygen species are involved in resistance responses of wheat to the Russian wheat aphid. J. of Plant Physiol. 163:1118-1125.

Moloi, M.J., van der Westhuizen, A.J. 2008. Antioxidative enzymes and the Russian wheat aphid (Diuraphis noxia) resistance response in wheat (Triticum aestivum). Plant Biol. 10:403-407.

Moloi, M.J., van der Westhuizen, A.J. 2014. Involvement of nitric oxide in the Russian wheat aphid resistance response of wheat. Cereal Res. Commun. 42:119-125.

Pucherelli, S.F., Peairs, F.B., Merrill, S.C., Randolph, T.L. 2011. Russian wheat aphid (Homoptera: Aphididae) reproduction and development on five non-cultivated grass hosts. Arthropod-Plant Interactions 6:67-73.

Saito, S., Yamamoto-Katou, A., Yoshioka, H., Doke, N., Kawakita, K. 2006.Peroxynitrite generation and tyrosine nitration in defence responses in tobacco BY-2 cells. Plant and Cell Physiol. 47:689-697.

Simaei, M., Khavari-Nejad, R.A., Saadatmand, S., Bernard, F., Fahimi, H. 2011. Effects of salicylic acid and nitric oxide on antioxidant capacity and proline accumulation in Glycine max L. treated with NaCl salinity. African J. of Agricultural Res. 6:3775-3782.

Song, F., Goodman, R.M. 2001. Activity of nitric oxide is dependent on, but is partially required for function of, salicylic acid in the signalling pathway in tobacco systemic acquired resistance. Mol. Plant Microbe Interact. 14:1458-1462.

Tolmay, V.L. 1995. The inheritance and mechanisms of Russian wheat aphid (Diuraphis noxia) resistance in two Triticum aestivum lines. MSc thesis. University of the Orange Free State, Bloemfontein, South Africa.

Tuteja, N., Chandra, M., Tuteja, R., Mishra, M.K. 2004. Nitric oxide as a unique bioactive signalling messenger in physiology and pathophysiology. J. of Biomedicine and Biotechnol. 4:227-237.

Walters, M.C., Penn, F., Du Toit, F., Botha, T.C., Aalsbersberg, K., Hewitt, P.H., Broodryk, S.W. 1980. The Russian wheat aphid. Farming in South Africa, Leaflet Series, Wheat G3:1-6.

Wink, D.A., Cook, J.A., Pacelli, R., Liebmann, J., Krishne, M.C., Mitchell, J.B. 1995. Nitric oxide (NO) protects against cellular damage by reactive oxygen species. Toxicology Letters 82-83:221-226.

Yamasaki, H., Sakihama, Y. 2000. Simultaneous production of nitric oxide and peroxynitrite by plant nitrate reductase: in vitro evidence for the NR-dependent formation of active nitrogen species. FEBS Letters 468:89-92.

Zieslin, N., Ben-Zaken, R. 1991. Peroxidase, phenylalanine ammonia-lyase and lignifications in peduncles of rose flowers. Plant Physiol. and Biochem. 29:147-151.

Zottini, M., Costa, A., De Michele, R., Ruzzene, M., Carimi, F., Lo Schiavo, F. 2007. Salicylic acid activates nitric oxide synthesis in Arabidopsis. J. of Exp. Bot. 58:1397-1405. 